Hard copy $(\mathrm{HC})$

Microfiche (MF)

3 July 65
$\$$ g 00

150 .

\title{
$N \operatorname{SC}-347$
}

THE ISOTOPIC ABUNDANCE AND CONTENT

OF SUIFUR IN METEORITES *

by F. R. Kaplan ${ }^{l}$ and J.R. Hulston ${ }^{2}$

ABSTRACT

Twenty

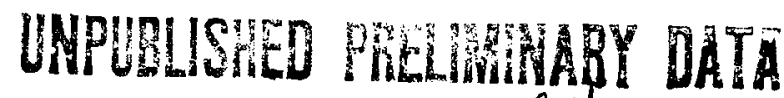
meteorites were studied in the iron

(Hexahedrites and Octahedrites) and stony (Enstatite achondrite, Carbonaceous, Enstatite and Olivine chondrites) families. The iron meteorites contain troilite as the chief sulfur component and the $\delta S^{34}$ ranges from 0 to $0.6 \%$ with respect to Canyon Diablo troilite. Stony meteorites demonstrate a wide variety of sulfur compounds including water and acid soluble sulfides, elemental: sulfur, water and acid soluble sulfates and unidentified components soluble only in aqua regia. The $\delta s^{34}$ content of the isolated compounds varies from +2.5 to $-5.5 \%$ with respect to Canyon Diablo. The weighted average for ali components of each meteorite, however, falls within $\pm 1 \%$ of Canyon Diablo. The $s^{33}$ distribution closely foliows $\mathrm{s}^{34}$. The data suggest that differentiations have occurred in the meteorites starting from a single source

Division of Geological Sciences, California Institute of Technology, Pasadena, California.

Du jartment of Physics, McMaster University, Hamilton, Oniario, Canada.

* Contribution No. 1333 of the Division of Geological Sciences, California Institute of Technology, Pasadena, California. 
of sulfur. There is no evidence for biological activity having occurred in the meteorite, either from the distribution of sulfur compounds or from the isotope abundance data.

This study has been supported by National Aeronautics and Space Administration Grant NsG 347/05-002-006.

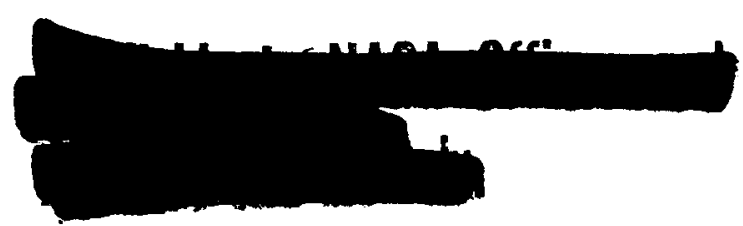




\section{INTRODUCTION}

Sulfur is a common and often important constituent of many meteorites, and since it is found in a number of minerals and sometimes occurs in various valence states is one meteorite specimen, its distribution may closely reflect the history of the meteorite. Isotope studies in the past on meteoritic sulfur have generally shown very constant values for the $\mathrm{s}^{34} / \mathrm{s}^{32}$ ratio (Macnamara and Thode, 1950; Vinogradov, Chupaskin and Grinenko, 1957; Ault and KuIp, 1959; Thode, Monster and Dunford, 1961; Jensen and Nakai, 1962). Most reliable results fall within $\delta \mathrm{S}^{34} \pm 1.0 \%$ of an average value. As a consequence, it has been realized that meteoritic sulfur can be used as a primary standard for sulfur isotope studies and all such results are now usually expressed relative to the meteoritic sulfur being used as the standard by the particular investigator. As slight variations do exist, it has been suggested (Ault \& Jensen, 1962) that only Canyon Diablo troilite be chosen as the primary standard.

Isotope studies on meteoritic sulfur have been conducted either with the trolilte nodules of iron meteorites, or the total components in the stony meteorites from which slizfur dioxide was separated by combustion. Smali 
significant variations in the isotope ratios of the order of $0.2 \%$ were detected by Thode, Monster and Dunford (196I) whereas larger variations are generally thought to result from experimental errors.

The significance of this fact goes beyond the use of meteoritic sulfur as merely a sultable standard for mass spectrometry, and indicates that sulfur had undergone no fractionation in its extra-terrestrial history and should therefore also depict the original sulfur isotope ratio of the earth prior to the formation of a hydirosphere. All subsequent processes on earth from igneous activity to blological processes, in which sulfur compounds are involved, must therefore relate back to the average $\mathrm{s}^{34} / \mathrm{s}^{32}$ ratio of meteorites.

Isotopic measurements by Dufresne and Thode (Anders, 1963) on sulfate and elemental sulfur from the carionaceous chondrite Orgueil, Indicated the former to be ${ }_{0} s^{34}-1.3^{\circ} \% 0$ and the latter $+3.04 \%$. Jensen and Naka1 (1962) found an average of $\delta \mathrm{s}^{34}-2.1 \%$ for a magnesium sulfate sample provided them by Dr. Brian Mason and isolated by Lawrence $S_{m i t h}(1876)$ presumably about eighty years ago.

As little attempt had been made to separate the various sulfur constituents from meteorites for analytical 
and isotope measurements, the study was inftiated in this direction. It was hoped to characterize some of the major sulfur constituents and at the same time separate them. These compounds were then prepared for isotope analysis by mass spectrometry. A preliminary, report of the results has been given elsewhere (Kaplan \& Hulston, 1963). The investigation attempis to answer (a) whether individual sulfur compounds are fractionated relative to each other and to the weighted average, (b) if any Iarge fractionations exist similar to these found on earth, (c) if there is a trend in the fractionation pattern which might indicate biological activity, and (a) what evidence exists that isotopic variations may have occurred during nucleogenesis.

Over twenty meteorites were investigated, representing types in which sulfur is often an important constituent.

METHODS

Pre-analytical treatment

Since most of the meteorites were obtained from museurn or university collections, their history during storage was generally not accurately known except for 
the most recent falls. Whenever possible specimens were chosen not to include any fusion crust or identification markings, which are quite common on museum samples. Any obvious impurities were removed with a clean steel chisel and the specimen wiped carefully with glazed paper to remove adnering particles. Stony meteorites were ground to a Ine powder with an alumina mortar and pestle.

Chondrules were removed from chondrites by gently crushing the meteorite, picking out the larger spheres and rolling out the smaller ones on an inclined sheet of glazea paper. When spherical particles no longer separated easily from the matrix, the material was studied with a low power binocular reflecting microscope and chondrules or sections of chondrules selected with finetippea forceps. The specimen was further crushed and the process repeated several times until the matrix was of a fine silt size. The chondrules were cleaned of loosely adnering matrix with a low powered ultrasonic disintegrator.

Troilite nodules were removed from the iron meteorites with a dental drill.

Sulfur analysis

Carbonaceous chondrites were generally dried over phosphorous pentoxide under vacuum prior to analysis, 
other meteorites were not because of their low water content, but a separate fraction was dried in order to present all values relative to the dry weight.

Iron meteorites.--The sulfide was removed from the troilite chips by action of hot $4 \mathrm{~N}$ hydrochloric acid in a closed vessel. Oxygen-free nitrogen was continuously blow in to remove the liberated hydrogen sulfide which was absorbed in a $5 \mathrm{~N}$ silver nitrate solution. The resulting silver sulfide was filtered on a sintered glass filter, washed with water, then with a $1: 1$ solution of ammonium inydroxide and then water again. It was dried at $105^{\circ} \mathrm{C}$ and was then stored in preparation for combustion to sulfur àıxide.

In the case of Coahuila the residue left after $\mathrm{HCl}$ reaction was oxidized with aqua regia and the sulfate precipitated as barium sulfate from the filtrate.

Carbonaceous and other chondrites.--An attempt was nade to characterize as many of the groups of sulfur compolincis as possible. The sequential steps generally followed were:

1. Extraction with 60:40 benzene-acetone. The extraction was generally carried out for 24 hours either in a Soxhiet apparatus or by refluxing the meteorite powder directly in the solvent. Since the sample weight was almost always under 10 grams, this method was considered sufficiently efficient. 
The solvent was then elther directly evaporated, to yiela elemental sulfur, as in the case of Orguell 2 (HU 4), Richardton and Karoonda, or else passed down a colloldal copper column (Blumer, 1957) which preferentialiy removed the sulfur as copper sulfide. The sulfur and copper sulfice were oxidized first with bromine and then aqua regia to sulrate. This was precipitated as barium sulfate.

2. Extraction of water-soluble sulfates. In the carbonaceous chondrites an attempt was made to extract water-soluble sulfates by refluxing the specimens, after organic solvent extraction, with deoxygenated water from 8 to 24 hours. At this stage a few drops of 10\% cadmium acetate were added to the extract to detect any soluble sulfides; none was detected except in the enstatite meteorites. Soluble sulfate was precipitated as barium sulfate from the solution.

3. Reaction with $5 \mathrm{~N} \mathrm{HCl}$. The meteorite specimen was then refluxed with about $100 \mathrm{mI} 5 \mathrm{~N} \mathrm{HCl}$ for 24 hours with a current of oxygen-free nitrogen being passed through the system. The released hydrogen sulfide was captured in a $5 \mathrm{~N} \mathrm{AgNO}_{3}$ solution as silver sulfide. It was assumed that this process Ilberated the sulfide from trolite.

4. Acid-soluble sulfate. The acid solution was then filtered or centrifuged and acid-soluble sulfate precipitated as barium sulfate. 
5. Second elemental sulfur extraction with benzene. The washed meteorite residue was dried at room temperature under vacuum and re-extracted with benzene. The solvent extract was evaporated to a small volume ( $10 \mathrm{cc}$ ) and elemental sulfur separated on a colloidal copper column.

6. Third elemental sulfur extraction of meteorite resicue with 60:40 acetone-methanol. The meteorite residue was next extracted with a 60:40 acetone-methanol mixture to remove the most polar organic components (Kaplan, Degens \& Reuter, 1963). This sometimes resulted in a dark phenolic extract in which elemental sulfur was dissolved. The sulfur was separated on the colloidal copper column.

7. Aqua regia oxidation. The remaining meteorites resialie was finally oxidized with aqua regia by prolonged slow boiling. In most cases this caused the solution of most of the metals with the decomposition of some of the silicates, leaving a white insoluble residue--probably silica with some silicates. The solution was evaporated to near dryness, $10 \mathrm{ml}$ concentral $\mathrm{HCl}$ added, and bolling continued to almost complete evaporation to remove excess nitric acid; $50 \mathrm{ml}$ water was then added and barium sulfate precipitated in the filtrate with barium chloride solution. 
In some cases where the organic content seemed very low and there was no reason to suspect elemental sulfur, steps 1,5 and 6 were omitted. The data given in the section on RESUITS include comments regarding which extract contalned the elemental sulfur.

Chondrules.--The chondrules were crushed to a fine powcer in an alumina mortar and reacted with $4 \mathrm{~N}$ hydrochloric acid to remove sulfides, as with the troilite nodules.

The insoluble residue of Richardton and Bjurbole was further oxidized with aqua regia and the solution tested for sulfates.

Enstatite chondrites and achondrite.--Since there are reports that oldhamite (calcium sulfide) is present in enstatite meteorites (Wiik, 1956) and also alabandite (manganese sulfide; Dawson, Maxwell \& Parsons, 1960) the procedure for analyzing these specimens was somewhat changed.

Norton County \& Hiaittis. To the powdered meteorite was added bolling oxygen-free water and a stream of oxygen-free nitrogen was passed through the reaction vessel. The mixture was heated to near boiling for 3 hours and evolved hydrogen sulfide captured in a solution of silver nitrate as silver sulfide. The aqueous extract of the meteorite was then filtered rapidiy on a Bllchner 
funnel and the filtrate allowed to run into a flask containing I mI of a concentrated cadmium acetate solution to trap the soluble sulfide. The cadmium sulfide was then decomposed with hydrochloric acid and the hydrogen sulfide absorbed in the first silver nitrate trap.

The residual meteorite was then refluxed with $4 \mathrm{~N}$ $\mathrm{HC} i$ and acid-volatile sulfide removed with nitrogen anò absorbed in silver nitrate solution.

The filtrates from the water and acid extracts were tested for soluble sulfates with barium chloride.

Following these reactions the meteorite residue was oxidized with aqua regia and sulfate precipitated from the filtrate with barium chloride.

Abee.--An attempt was made to separate didhamite from alabandite by the following method. The ground meteorite was shaken for 10 minutes with $10 \mathrm{ml}$ boiling water, filtered rapidy on a Bllchner funnel and washed with $900 \mathrm{ml}$ boiling water into a riask contalning $30 \mathrm{ml}$ of 10\% cadmium acetate solution. The cadmium sulfide was later converted to silver sulfide. Elemental sulfur was noted to crystallize on the walls of the flask as the filtrate cooled. This was separated by filtration and extraction with toluene after which 1 t was recrystalized. To the residual meteorite was added $100 \mathrm{ml}$ cold deoxygenated water and carbon dioxlde blown through the 
mixtire--no evolution of hydrogen sulfide occurred. An addition of $0.25 \mathrm{ml}$ acetic acid was made and evolution begai: slowly and increased on heating. Bubbling of $\mathrm{CO}_{2}$ conisinued until no further evolution of hydrogen sulfide could be detected in the silver nitrate trap. The above two sulfides were combined and termed calcium sulfide. To the meteorite was next added $100 \mathrm{ml}$ of a $20 \%$ acetic acid solution and carbon dioxide was bubbled through the reaction vessel for about 20 hours until no further nyarogen sulfide was evolved.

Next $70 \mathrm{ml}$ concentrated hydrochloric acid was added to the reaction mixture and a very rapid evolution of hydrogen sulifie occurred. The hydrogen sulfide was trapped in a silver nitrate solution.

The remaining meteorite residue was oxidized with aqua resia. All filtrates, after water, acid, and aqua regia reactions, were tested for sulfate.

Chemical differentiation between alabandite and troilite. Since presumably only small quantities of alabancite are present in the Abee meteorite (Dawson, Maxwel1 \& Parsons, 1960), It was assumed that only a chemical method would effectively separate it from the troilite. Trials with troilite from Canyon Diabio showed that acetic acid did not react with it to liberate hydrogen sulfide, even when the reaction mixture was heated. 
A terrestrial alabandite ore from French Mine, Arizona, reacted slowly with $5 \%$ acetic acid in the cold and more readily with $20 \%$ acetic acid. Heating the mixture accolerated the release of hydrogen sulifde. Ehole.--Since elemental sulfur was suspected from this meteorite, it was first extracted with an 80:20 benzene-methanol mixture. It was then reacted with $0.5 \%$ hot acetic acid and the released hydrogen sulfide removed in a stream of nitrogen and captured. Next it was reacted with 5\% acetic acid flrst in the cold and then by heating. The sulfide further released was captured. Finaily, the meteorite residue was reacted with $4 \mathrm{~N}$ hydrochlc-:c acid. The three sulfide fractions obtained were kept separate. All acld filtrates were tested for sulfate.

The ary meteorite was re-extracted with benzenemethanol (20:80) and finally oxidized with aqua regia and sulfate in the filtrate as previously.

\section{Isotope measurements}

All barium sulfates were reduced to hydrogen sulfide with a hypophosphorous-hydroiodic acid mixture and converted to silver sulfide following the description of Thode, Monster and Dunford (1961). 
Sulfur dioxide, for mass spectrometer measurement, was prepared by an adaptation of the method described by Rafter (1957) in which the silver sulfide was burnt at $1200^{\circ} \mathrm{C}$ in a stream of oxygen.

Some of the samples were measured on the mass spectrometer as the gas sulfur hexafluoride $\left(S F{ }_{6}\right.$ ) using an adaption of the method developed by Hoering (1962). This enabled small samples of the order of $1.0 \mathrm{mgm}$ sulfur (8 $\mathrm{mgm} \mathrm{Ag}_{2} \mathrm{~S}$ ) to be studied. It also had the advantage of allowing $\mathrm{s}^{36}$ to be measured, since there was no interference by other overlapping isotopic ion species (e.g. oxygen isotopes in $\left.\mathrm{SO}_{2}\right)$. The $\mathrm{SF}_{6}$ was produced in an all-metal vacuum system by passing dry fluorine gas over $A g_{2} S$ at room temperatures for 30 minutes and collecting the $\mathrm{SF}_{6}$ produced in a trap cooled by liquid oxygen. The $\mathrm{SF}_{6}$ was then purified by gas chromatography using a colunn packed with molecular sieve type $5 \mathrm{~A}$ heated to $150^{\circ} \mathrm{C}$. The method is described in deta1z elsewhere (Hulston \& Thode, 1965).

The $\mathrm{SO}_{2}$ and $\mathrm{SF}_{6}$ samples were measured on a 6-inch mass spectrometer employing simultaneous collection and sample switching techniques as described by Wanless and Thode (1953). The ionic species $\mathrm{SO}_{2}{ }^{+}$and $\mathrm{SF}_{5}{ }^{+}$were used for these measurements. All results are quoted as ${ }_{0} \mathrm{~s}^{34}$ values ciesined by: 


$$
\delta S^{34}(\%)=\left(\frac{\left(s^{34} / s^{32}\right) s \text { sample }}{\left(s^{34} / s^{32}\right) s t a n d a r d}-1\right) \times 1000
$$

The standard $\mathrm{SO}_{2}$ and $\mathrm{SF}_{6}$ gases used were both prepared Irom the troilite phase of the Canyon Diablo meteorite. The ${ }_{0} \mathrm{~S}^{34}$ value thus expresses the difference in parts per thousand between $\mathrm{s}^{34} / \mathrm{s}^{32}$ ratio of the sample as compared to the $\mathrm{s}^{34} / \mathrm{s}^{32}$ ratio of the Canyon Diablo troilite.

\section{RESULTS}

Description of meteorites

Some properties of the meteorites studied are given in Table 1. In general there does not appear to have been any extraneous adition of sulfur to the specimens during storage. Changes, especially oxidations, may well have occurred within the samples during storage. This is shown by the presence of sulfate in many meteorites (Taile 2) and by ferric hydroxide often associated with lawrencite $\left(\mathrm{FeCl}_{2}\right)$ irom which it is derived. Fresh surfaces often showed rust spots, especially if metallic iron was present. Troilite grains were sometimes covered with a yellow film suggesting slight oxidation at the exposed surfaces. In general, metallic iron appeared to oxidize more readily than the troilite. Inadequate 
protection of Type I carbonaceous chondrites results in efflorescence of white crystals on the surface during storage (M. H. Hey, personal communication).

Iron meteorites

The most abundant form of sulfur in the iron meteorites is troilite. Reports have been made for the presence of dauoreelite $\left(\mathrm{FeCr}_{2} \mathrm{~S}_{4}\right)$, particularly in Coahuila (Prior, 1953), but only traces of a nonhydrochloric volatile sulfur component could be separated from this meteorite in the present study (Table 3). Since Nichiporuk ana Chodos (1959) have shown that pyrrhotite is also a common constituent of many troilite nodules including Coahuila, the sulfur remaining after hydrochloric acid treatment may arise from various minerals.

A number of trolite nodules from iron meteorites were analysed inwich the ratio of Fe:S was reported to de Greater than lisual (Nichiporuk and Chodos, 1959). These are the Toluca, Indian Valley ana Ballinoo meteorites. Nichiporuk (personal communication) thought this enrichment in iron may indicate that sulfur had been preferentially removed and may indicate a fractionation process.

The isotope data in Table 3 show a remarkably constant value for the troilite sulfur of the iron meteorites. The ${ }_{0} \mathrm{~S}^{34}$ results all fall within 0.0 to t0.6\% of Canyon 
Diablo which is the standard; the average for the six samples being given as t0.2\%

Carbonaceous and other chondrites

The distribution of sulfur in the chondrites appears to be quite complex. It is generally assumed that Types I anu II carbonaceous chondrites have three valance states of sulfur demonstrated by sulfide, elemental sulfur, and sulfate; the other chondrites are thought to have only troilite. Mason and Wilk (1962), however, demonstrated that pentlandite (Fe, N1) ${ }_{9} S_{8}$ was the major sulfide mineral in Karoonda (olivine chondrite). They demonstrated the presence of traces of pyrite and chalcopyrite, existing as inclusions associated with the pentlandite. The presence of a number of sulfide minerals in traces was detected in polished thin section by Ramdohr and-hul (196) .

The variability of sulfur distribution in stony meteorites can be seen from the present results (Tables 2 and 3) and from Mason (1962, 1962-1963), and may in part reflect the uneven distribution of the solid phase as suggested by Wiik (1956).

The analytical procedure used to extract the sulfur was outined in order to separate as many of the components as possible. In all meteorites, except the enstatite 


$$
\text { Nortin County and Ehole, }
$$

chondrites ${ }_{\lambda}$ it was assumed that no water-soluble sulfide phase existeà.

Carbonaceous chondrites were first extracted with an urganic solvent mixture in order to remove elemental sulfur and then a series of other extractions, as outlined in the Methoas to remove other components. The results seen in Table 2 seem to confirm Mason's (1962-1963) generalization that Type I carbonaceous chondrites are enriched in the sulfate phase, Type II in elemental sulrur, and Type III in troilite. There appears to be little douid that Mype III chondrites have troilite as the major, anci perhaps only, phase in most stones. In the case of Type I carbonaceous chondrites insufficient evidence exists, since only one stone, Orgueil, was investigated in the present study and the results differ from those given by DuFresue and Anders (1962) for the same meteorite. The elemental sulfur seems to be distributed as a coating on the silicate mineral grains and is easily removed by organic solvent extraction. The most complex case was presented by the Type II carbonaceous chondrites. Here, sulfur seems to exist in numerous phases. Of the three specimens studied (Table 2) trollite was least abundant. The procedure used for extracting Mighei and Cold Bokkeveld was different from that used for Murray. In this latter case the meteorite was not re-extracted with organic 
solvents after hydrochloric acid treatment and this may account for the large component listed as residual sulfur (Table 2). A small specimen of a stone obtained from a separate source (Dr. E. P. Henderson, Smithsonian Institute, Washington, D. C.) was extracted later by the same procedure as for Mighei and Cold Bokkeveld and although no quantitative data are available, elemental sulfur was extracted by the second organic solvent extraction and no residual sulfur could be detected after aqua regia oxidation. It is therefore probable that the sulfur Iisted as residual sulfur in Table 2 is the organic solvent extractable sulfur. Due to lack of meteorite specimens, this could not be tested further quantitatively either in Murray or in Mokoia, where the same condition may pertain.

The ordinary chondrites contain trollite as the most abundant phase. Residual sulfur is most likely due to varying amounts of nickel sulfide as found in Karoonda, or even perhaps nonhydrochloric acid volatile iron sulfides. The presence of sulfates or elemental sulfur as found in Richardton (Table 3) is probably due to oxidation of reduced sulfur during storage of the sample after falling. This is especially true in the case of Richardton where marked oxidation was visible. However, it must be noted that elemental sulfur was detected in this meteorite 
Dy the second organic solvent extraction after hydrochioric acici treatment, similar to the case of Mighei and cold Bokkevela.

The enstatite choncirites are generally accepted as being highly reduced. This is confirmed by the presence of water soluble sulfice probably in the form of calcium sulficie (oichamite). The occurrence or sulfate may be related to this unstable sulfur component. The residual sulfur in all cases may represent nickel sulrides, since the cisid extracts of the meteorite were a deep green color. The presence of manganese sulfide, alabancite, has been suggested by Dawson et al. (1960) to exist in Abee. Its removal was attempted in this meteorite and in inole by reaction with weak acetic acid solution. This reaction was carried out on the basis that trollite extracted from Canyon Diablo iron meteorite did not liberate hydrogen sulfide by reaction with acetic acia, both dilute and concentrated, whereas terrestrial alabandite dici so. The large discrepancy between the values found by Dawson et a]. (1960) and the present work suggests that a more thorough investigation of this problem is

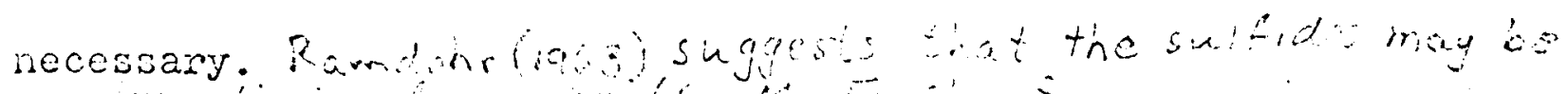

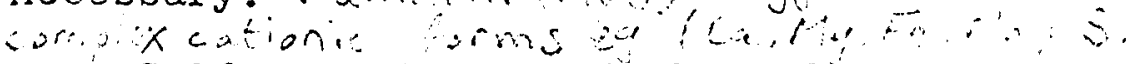
Sulfur in the chonärules of ordinary chondrites and Iype III carbonaceous chondrites appears to be present largely in the form of troilite. No other component couid 
be extracted. Adhering troilite grains were removed mechanically wherever possible. Microscopic observations clearly showed that the troilite content was variable. Photographs of chondrules by Anders and Goles (1961) demonstrate the variable distribution of the sulfide.

\section{Achondrites}

An unsuccessful attempt was made to separate troilite from Pasamonte meteorite--a pyroxene-plagioclase achondrite. From $1.4 \mathrm{~g}$ of a heavy mineral fraction separated from the meteorite by settling out in methylene iodide, only $0.001 \% \mathrm{~S}$ was removed.

Norton County, an enstatite achondrite, yielaed no water-soluble sulfides but did produce a water-soluble sulfate which probably represents the oxidized phase of olihamite. The acid extracts were green indicating the leaching of nickel. The residual sulfur is probably a hydrochloric acid insoluble iron nickel sulfide. Metal fragments up to $3 \mathrm{~mm}$ in diameter were separated, indicating the heterogeneous nature of this meteorite. This probably explains why the calculated total sulfur content which was measured using 16 of of meteorite differs from the total by direct analysis from 0.8 is meteorite.

Isctopic variation

Variation oi $\delta S^{34}$ in extracts of the meteorites 
studies varied from t2.6 to $-5.6 \%$ (mables 2 and 3 ). A weighted average was taken for each meteorite and it can be seen to lie between +0.5 and $-0.7 \%$. The direct total analysis fails close to 0 . The data in Ficure 1 and 2 clearly show that the isotopic ratio $\mathrm{s}^{34} / \mathrm{s}^{32}$ is not constant for each compound and that the variation does not seem to follow any clear pattern, but that the average of the separate components falls close to zero. The discrepancy that exists between the calculated average and the direct measurement of the whole meteorite in the case of Norton County may reflect a heterogeneous distribution of components in the different fragments analyzed. The variation in $\delta \mathrm{s}^{34}$ from +1.0 to $3.3 \%$ for elemental sulfur extracted from three separate fragments of Orgueil meteorste illustrates the spread.

From Figures $I$ and 2 it can be seen that there are no definite trends for isotope variation of the different components. There may be some significance, however, to the fact that in the Pype I and Type II carbonaceous chondirftes the sulfide phase had a positive $\delta \mathrm{s}^{34}$ value and the sulfate a negative $\delta \mathrm{S}^{34}$ value relative to Canyon Diablo. In Mokoia (Type III) the reverse was measured. The negative value for sulfate may indicate that it was derived from a volatile sulfide phase in the meteorite through preferential diffusion and oxidation of the 
lighter molecule. This may also explain the very negative $\delta \mathrm{S}^{34}$ value for the sulfate isolated from Norton County (maise 3).

The values for $\delta S^{34}$ in troilite from the chondrules of Richarditon and Bjurbole (Table 3) were similar to the ${ }_{5} \mathrm{~S}^{34}$ values of troilite in the matrix. This may indicate a conmon source for the sulfide phase.

The troilite of iron meteorites has a very constant value near os $\mathrm{s}^{34} 0.0 \%$. On the other hand a terrestriai troilite from Del Monte Country, California, one of the rare examples of such a mineral, gave a value of $\delta \mathrm{S}^{34}=$ $-2.3 \%$. (Table 3) showing that it was unlikely to have been derived in the past from a meteorite.

In addition to $\mathrm{s}^{34}$, mass spectrometer measurements have also been made on $\mathrm{S}^{33}$ by using both the $\mathrm{SO}_{2}$ and $\mathrm{SF}_{6}$ techriques (Hulston and Thode, 1965). The data for the relative aistribution are given in Figure 3.

\section{DISCUSSION}

Of particular interest is the presence of eiemental sulfur in the carbonaceous meteorites. It appears that the distribution may be different in Type I and Iype II. -is the former, the sulfur is present on the surface of mineral grains, and can easily be removed by an organic 
solvent extraction. In the rype II chondrites, an organic solvent extraction alone could not remove the sulfir. It was only after the meteorite was hydrolyzed in hydrochloric acid that organic solvent extraction was successFul. After hydrolysis, the organic residues seemed more solusic in polar than nonpolar organic solvents (Kaplan, Degens and Reuter, 1963) and the nature of these compounds suggests that they may have heterocyclic structure. The elemental sulfur may therefore be organically bounci in such a case. Alternatively the sulfur is captured within crystal grains and only liberated when these have deen partially destroyed by acid treatment. Since it is difiicult to envisage a complete removal of organically bolind sulfur as elemental sulfur by acid treatment, it may be assumed for the present, that elemental sulfur exists only in a relatively unavailable form in Type II carbonaceous chondrites.

The data presented in Tables 2 and 3 and Figures $I$ and 2 show that the $\delta S^{34}$ for the total meteorite agrees to within t0.7 of the value derived by computation. This value was derived by multiplying the isotope ratio of each component by its.proportion of the total sulfur content and summing. The general close agreement indicates that no important components could have been lost auring the Iaboratory separation. 
One ractor that may produce anomalous fractionation Iactors is the analytical procedure. If, during the separation of the components, there was partial separation only, this may account for discrepancies. The fact that the iron meteorites, however, showed constant $s^{34} / s^{33}$ ratios after release of sulfide from troilite would tend to argue against this. In addition, it is difficult to see how solid phases such as suliate or elemental sulfur could be fractionated by solvent extraction, since there are no kinetic or equilibrium phenomena involvea.

The data show no clear evidence for microbiolosical suliate reduction of the type known in terrestrial deposits or laboratory experiments. In such a case the suliate is invariably enriched in the heavier isotope. Mokoia may De the only exception to the other data, since here sulfate showed an enrichment in the heavier isotopes. The results do not, however, eliminate the possibility or a microbial sulfur cxidation of sulfides and elemental sulfur to suifate. Other lines of evidence would have to be brought forward to support this contention.'

Trie constant average of $\mathrm{s}^{34} / \mathrm{s}^{32}$ composition of the total sulfur in meteorites studied, strongly indicate that the sulfur incorporated into the planetary body or bodies auring their formation arose from a common source. 
The presence of isotopic variation and the averaginis out of the values to a constant for any single meteorite fragme: stronify suggests that reactions have occurred in a closed system without any appreciable losses of individual components. The data also argue against addition of sulfur from external sources.

Further support for in situ fractionation by chemical processes comes rrom the study by Hulston and Thode (1965) of the other stable isotopes of sulfur $\left(s^{33}\right.$ and $s^{36}$ ) relative to $\mathrm{s}^{32}$ and $\mathrm{s}^{34}$. The results inaicate no anomaicus enpichment of either of these isotopes. Data plotted in Figure 3 showing the rulationship between $\delta s^{33}$ and $\delta s^{34}$ yield a straight line with a slope of 0.51 , identical with that proposed by theory.

The factors outlined above are strong evidence against the formation or accretion of any significant amoints of sulfur in the meteorite parent body through processes that mây cause the anomalous enrichment of $s^{33}$ or $\mathrm{s}^{36}$ (Hulston ano Thode, 1965). 
ANDERS E. (1963) - On the Origin of Carbonaceous Chondrites. Annals, N.Y. Acad. Sci. 108, 514-533.

ANDERS E. and GOLES G.G. (1961) - Theories on the origin of meteorites. J. Chem. Educ. 38, 58-66.

AUIT W.U. and JENSEN M.I. (1962) - Summary of Sulfur Isotopic Stundartio. Published in Biogeochemistry of Sulfur Isotopes. Symposium of N.S.F. Yale Univ. Ed. M.I. Jensen.

AULT W.U. and KULP J.I. (1959) - Isotopic geochemistry of sulphur. Geochim et Cosmochim. Acta 16. 201-235.

BLUVIEA M. (1957). Removal of Elemental Sulfur from Hyärocarbon Fraction. Anal. Chem. 29, 1039-1041.

D.NSON K.R., MAXVELL J.A. and PARSONS D.E. (1960). A description of the Meteorite which fell near Abee, Alberta, Canada. Geochim. ei Cosmochim Acta 21, 127-144

DU FRESNC E.R. and ANDERS E. (1962). On the chemical evolution of the carbonaceous chondrites. Geochim. et Cosmochim Acta 26, 1085-1114.

YOERING T.C. (1962) (Personal comunication)

HULITON J.R. and THODE H.G. (1965). Variations in the ${ }^{33} \mathrm{~S}$ and ${ }^{36} \mathrm{~S}$ contents of Meteorites and their relation to Nuclear and Chemical affects - Submitted to J. Geoph. Res. 
JENSEN M.I. anã NAKAI N. (1962). SuIfur Isotope Meteorite Standards: Results and Recommendations. Published in Biogeochemistry of Sulfur Isotopes. Symposium of N.S.F. Yale University, Ed. M.I. Jensen.

KYPLAN I.R., DEGENS E.T. and REUTER J.H. (1963). Organic compounds in stony meteorites. Geochim et Cosmochim Acta 27. 805-834.

KAPEAN I.R. and HULSTON J.R. (1963). Isotopic Abundance and Content of Sulfur in Meteorites. G.S.A. Annual Meeting New York Abstracts. p. 89.

MACNAMARA J. and THODE H.G. (1950). Comparison of the isotopic constitution of terrestrial and meteoric sulfur. Phys. Rev. 78, 307-308.

MASON B. (1962). Neteorites, John Wiley and Sons, New York, 274 Pp. MASON B. (1962-1963). The Carbonaceous Chondrites. Space Science Reviews 1, 621-646.

WiASON B. and WIIK H.2. (1962). Descriptions of two Meteorites: Karoonda and Erakot. Amer. Mus. Novitates, No. 2115, $10 \mathrm{pp} \cdot$

MCNSTER J., DUFRESNE E.R., ANDERS E. and THODE H.G. (1965). Sulfur isotopic ratios of orgueil meteorite - To be publishea.

EXCHIPONUK W. and CHODOS A.A. (1959). The concentration of Vanadium, Chromium, Iron, Cobalt, Nickel, Copper, Zinc, and Arsenic in the Meteoritic Iron Sulfide Nodules. J. Geoph.Res. 64, 2451-2463. 
PRTOR G.T. (1953). Catalogue of Meteorites. British Wuseum, London, $432 \mathrm{pp}$ (second edition revised by M.H. Hey).

RAFTER I.A. (1957). SuIphur isotopic variations in nature. Pt. I - The preparation of sulphur dioxide for mass spactrometer examination. N.Z. J. Sci. Teci. 38B, 849-857.

RANDOFR 2. (1963). Opaque minerals in stony meteorites. $J$. Geophys. Res. 68, 2011-2036.

SMITH S.H. (1876). Researches on the solid carbon compounds.of nuteorites. Am. J.Sci. XI, 436-442.

TEODE H.G., MONSTER J. and DUNFORD H.B. (1961). Sulphur isotope geochenistry. Geochem. et Cosmochim Acta 25, 159-174.

W.NLISS R.K. and THODI H.G. (1953). A viass spectrometer for High Precision Isotope Ratio Determinations. J. Sci. Instrum. 30, $395-398$.

WIIK H.B. (1956). The chemical composition of some stony meteorties. Coocinimica et Cosmochim Acta 9, 279-289.

VINOGRADOV A.P.. CHUPAKHIN M.S. and GRINEKO V.A. (I957). SOMe data on the isotopic constitution of sulfur of sulfides. Geochemistry (Engl. Translation) No. 3, 221-225. 
Legenả to Figures

Figure 1. Distribution of $s^{34} / s^{32}$ among the different sulfur constituents in carbonaceous chondrites.

Figure 2. Distribution of $s^{34} / s^{32}$ among the different sulfur constituents in chondrites, achondrites, iron meteorites and terrestrial troilite from Del Norte County, California.

Figure 3. Variation in $s^{34}$ relative to $s^{33}$ in meteorites and terrestrial sulfur compounds used as standaras. The meteoritic samples were measured either in the form of $\mathrm{SO}_{2}$ or $\mathrm{SF}_{6}$. 
METEORITE

Type I

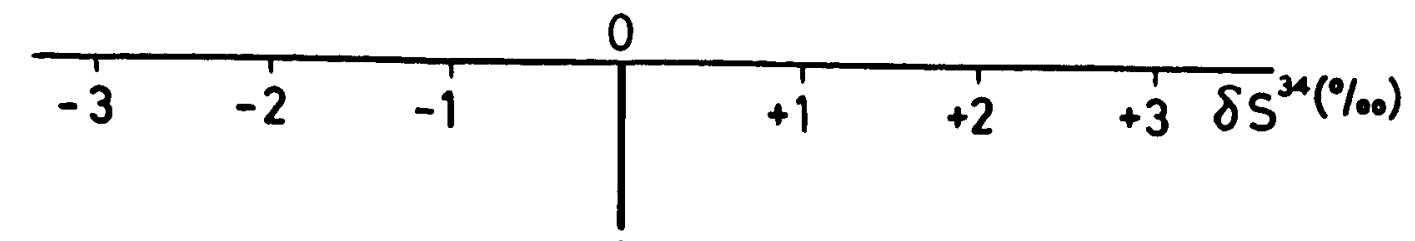

Orgueil

Type II

Mighei

Murray

$\Delta$

$\left\{\begin{array}{lll}\neq & 0 & 0 \\ \neq 0 & & 0\end{array}\right.$

Cold Bokkeveld

$\Delta$

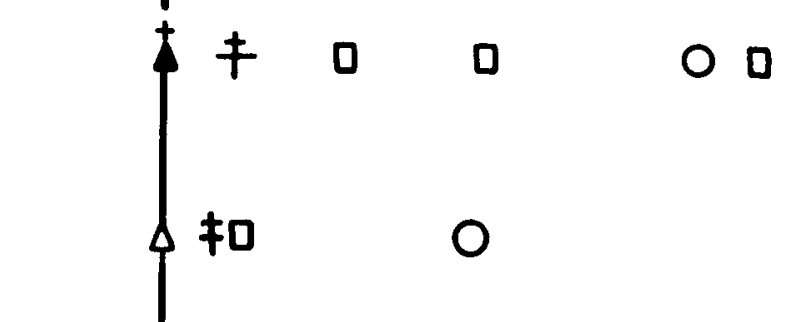

Type III

Mokoia

0

$f_{x+} \quad \Delta$

Felix

Warrenton

Karoonda

$\Delta$

$\Delta x$

0

D

$\square \neq \Delta$

0

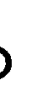

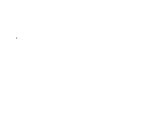




\section{CHONDRITES}

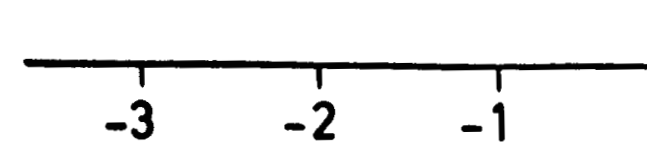

Abee

Hvittis

Bjurbole

Ehole

Richardton (a)

(b)

IRONS

Terrestrial $\mathrm{FeS}$

ACHONDRITE - Norton County

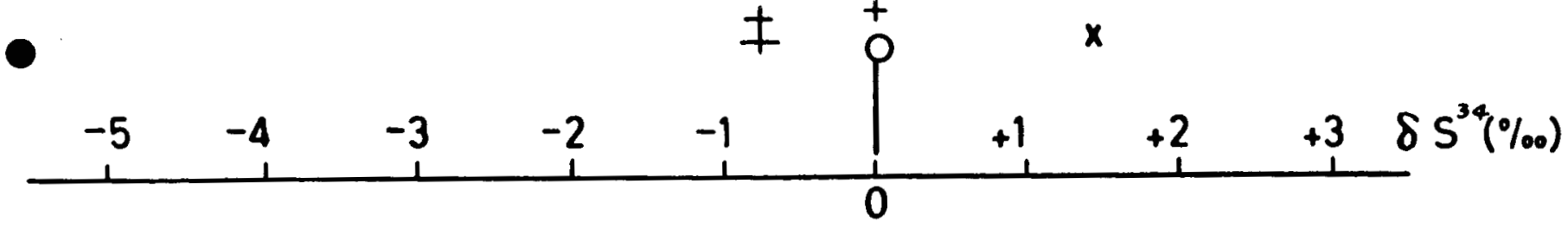
$\triangle \mathrm{SO}_{4}\left(\mathrm{H}_{2} \mathrm{OSOl}\right)$
$0 \mathrm{~S}^{\circ}$
O FeS
$x$ Residual $S$
$\oplus$ FeS in chondrules
$\neq$ Weighted average of total
- Other Sulfides

甲0

时年

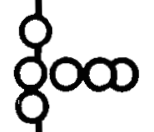




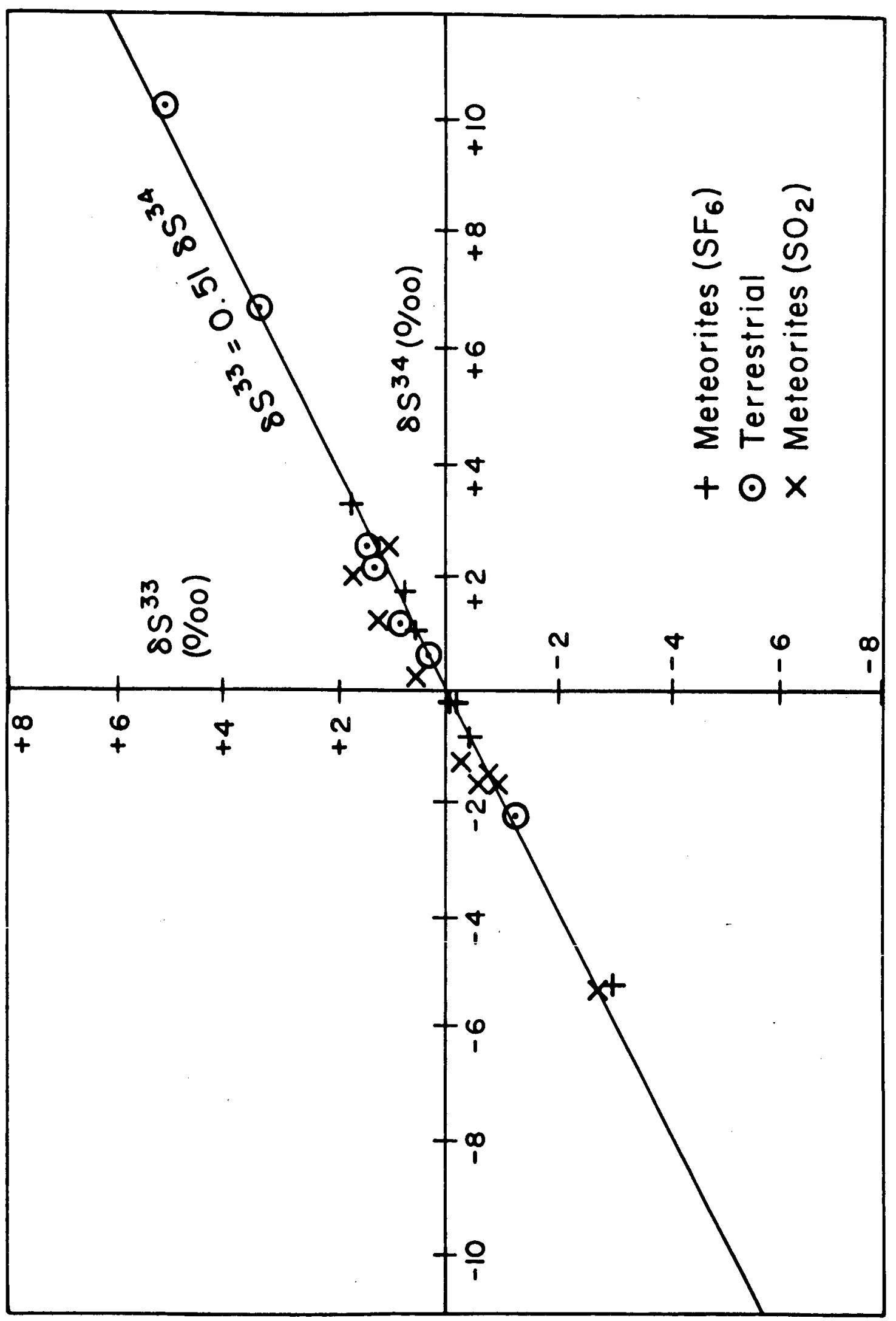




\begin{tabular}{|c|c|c|c|}
\hline Meteorite & & Type & or1 \\
\hline Orgueil & (a) & $\begin{array}{c}\text { Carbonaceous Chondrite } \\
\text { Type I }\end{array}$ & $\begin{array}{l}\text { B. Mason, } \\
\text { Am. Mus. } \\
\text { N.Y. }\end{array}$ \\
\hline$\underset{n}{\text { orgue }}$ & $\begin{array}{l}\text { (b) } \\
\text { (c) } \\
\text { (d) }\end{array}$ & & \\
\hline M1ghe1 & & $\begin{array}{c}\text { Carbonacoous Chondrite } \\
\text { Type II }\end{array}$ & $\begin{array}{l}\text { K.K. Ture } \\
\text { Yole Un1y } \\
\text { Dept. of }\end{array}$ \\
\hline Murray & & $\begin{array}{c}\text { Carbonaceous Chondrite } \\
\text { Type II }\end{array}$ & $\begin{array}{l}\text { Californd } \\
\text { Techne }\end{array}$ \\
\hline Cold Bokkeveld & & $\begin{array}{c}\text { Carbonaceous Chondrite } \\
\text { Type II }\end{array}$ & $\begin{array}{l}\text { K.K. Ture } \\
\text { Un18. }\end{array}$ \\
\hline Moko1a & & $\begin{array}{c}\text { Carbonaceous Chondrite* } \\
\text { Type III }\end{array}$ & $\begin{array}{l}\text { C.B. Moor } \\
\text { Univ. of } \\
\text { (Nininger } \\
\text { Coll } .)\end{array}$ \\
\hline Fel $1 x$ & & $\begin{array}{c}\text { Carbonaceous Chondrite } \\
\text { Type III }\end{array}$ & $\begin{array}{r}\text { Californd } \\
\text { Techr. }\end{array}$ \\
\hline Warrenton & & $\begin{array}{cl}\text { Carbonaceous Chondrite* } \\
\text { Type III }\end{array}$ & $\begin{array}{l}\text { K.K. Ture } \\
\text { UnIversit } \\
\text { Geology. }\end{array}$ \\
\hline Karoonda & & $\begin{array}{c}\text { Carbonaceous Chondrito* } \\
\text { Type III }\end{array}$ & $\begin{array}{l}\text { B. Mason, } \\
\text { Am. Mus. } \\
\text { N.Y. }\end{array}$ \\
\hline Lance & & $\begin{array}{c}\text { Carbonaceous Chondrite* } \\
\text { Type III }\end{array}$ & $\begin{array}{l}\text { K.K. Ture } \\
\text { Yale Un11 }\end{array}$ \\
\hline Abee & & Enstat1te Chondrite & $\begin{array}{l}\text { G.G. Gole } \\
\text { U.C.S.D., }\end{array}$ \\
\hline Hvittis & & Enstatite Chondrite & $\begin{array}{l}\text { K.K. Ture } \\
\text { Yale UnII }\end{array}$ \\
\hline Bjurbole & & $\begin{array}{l}\text { Olivine-Hypersthene } \\
\text { Chondrite }\end{array}$ & $\begin{array}{l}\text { B. Mason, } \\
\text { Am. Kus. } \\
\text { N.Y. }\end{array}$ \\
\hline
\end{tabular}




\section{TABLE 1 cuTE}

Condition and Description of Specimens

of Nat. H1story,

Small fragments without fusion crust. White efflorescence present $(3 \mathrm{~g})$.

"

$n$

$n$

klan, orsity, Goology.

a Inst. of logJ

klan, Yale

$\theta$,

Arizona, Meteorite

a Inst. of

ology

kian, Yalo

J, Dopt. of

of Nat. History,

kian,

orsity

La Jolia.

k1an, ersity

of Nat. H1story $\operatorname{sem} \theta(0.23 g)$

Isolated sulfate obtained from B. Mason extracted by J.L。 Smith (1876).

Black chondrite with few chondrules. White salt on surfaces. Specks of brown $\mathrm{Fe}_{2} \mathrm{O}_{3}$ visible $(4.3 \mathrm{~B})$.

Crushed specimen as powder stored in glass vial $(6.2 \mathrm{~g})$.

Sample broken from larger specimen. Some magnetic perticles appearing to contain sulfides. White salt visible $(6.8 \mathrm{~g})$.

Single fragment, fracture planes contalning white crystals, some brown spots of iron oxide visible. Chondrules dominant $(6.14 \mathrm{~g})$.

Crushed specimen as powder stored in glass vial $(1.8 \mathrm{~g})$.

Single fragment. Magnetic. Some oxidation. White salt visible under low power magnification $(1.7 \mathrm{~g})$.

Black easily fragmented specimen. Sulfides easily visible under low power magnification $(3.4 \mathrm{~g})$.

Single iragment. Magnetic. Some oxidetion $(2.5 \mathrm{~g})$.

Dense and hard. Polished surfaces show free metal and metal sulfide surfaces. Magnetic. No oxidation apparent $(7.9 \mathrm{~g})$.

$$
\text { As above }(5.38) \text {. }
$$

Grey chondrite containing $25 \%$ chondrules. Sulfides present in abundence. Some oxidation evident $(5.2 \mathrm{~g})$. 
Ehole

olivine-Bronzonite Chondrito

H. Suess,

U.C.S.D.,

R1cherdton

(a)

OIIvine-Bronzite

Chondrite

(b)

Norton County

Canjon Diablo

Toluca

Toluca

Merceditag

1.

Indian valley

Ballinoo

Coshu118

Terrestrial Troilite (a)

(a)

(b)

Iron - medium octabedrite

Enstatite Achondrite (calcium poor)

Iron - cosrse octahedrite

\section{)}

a)

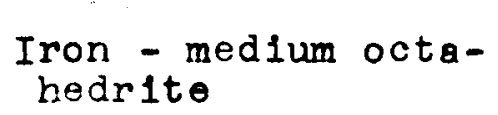

K.K. Turek Yale Un Ive

L. S1lver, California Technol

\section{TABLE I


Highly magnet 10. Fresh surfaces showed little oxidation or tarnishing. Some encrustations of salt. No chondrules $(3.8 \mathrm{~g})$.

Fragmented specimen. Obvious evidence of oxidation. Chondrules dominant ( $3 \mathrm{~g})$.

Some fusion crust st11l present $(7.5 \mathrm{~g})$.

Sample broken from larger specimen. Metal

(Fe or N1) fragments up to $3 \mathrm{~mm}$ diameter present. oxidation evident $(16.1 \mathrm{~g})$.

Fresh surface cut and trollite removed from nodule by drill.

Inst. of

ogy.

- Same -

- $\operatorname{Sam} \theta-$

$-\operatorname{sam} \theta-$

ruk,

Inst. of

ogy•

leteorite Co.

- Same -

ruk,

- Same -

Inst. of Technology.

- Same -

"

- Same -

Ian

- Same -

roity

Inst. of

iemoved by drill from clean surface of trollite。

OgJ.

geonite Chondrites.

TABLE I

CUT (4) 


\begin{tabular}{|c|c|c|c|}
\hline Meteor1te and Typo & Compouna Extracted & $\begin{array}{l}\text { Probable } \\
\text { Component }\end{array}$ & $\begin{array}{c}\text { Sample } \\
\text { No. }\end{array}$ \\
\hline \multicolumn{4}{|l|}{ Typ•I } \\
\hline \multirow[t]{7}{*}{ Orgue1l (a) } & $s^{0}$ lst extract & $\mathbf{s}^{\circ}$ & CM53 \\
\hline & $s^{\circ}$ and extract & $\mathrm{s}^{\circ} ?$ & CM5 4 \\
\hline & $\mathrm{SO}_{4}=\left(\mathrm{B}_{2} \mathrm{O} 801\right)$ & $\mathrm{Mg} \mathrm{SO}_{4}$ & CM19 \\
\hline & $\mathrm{SO}_{4}=(\mathrm{HCl}$ sol $)$ & $\mathrm{Ca} \mathrm{SO}_{4}$ & CM22 \\
\hline & $S=(\mathrm{HCl} \nabla O I)$ & Fes & CM2O \\
\hline & Residual s (aqua regla) & - & - \\
\hline & Total $\mathrm{S}$ & & HU2 /68 \\
\hline orgue1l (b) & $s^{0}$ & $\mathrm{~s}^{0}$ & $\mathrm{HO} 4 / 93$ \\
\hline orgue1I (c) & $\mathrm{s}^{0}$ & $\mathrm{~s}^{0}$ & $x / 203$ \\
\hline Orgue11 (d) & $\mathrm{SO}_{4}=(\operatorname{Sin} 1 \mathrm{th}, 1876)$ & $\mathrm{Mg} \mathrm{SO}_{4}$ & \\
\hline \multicolumn{4}{|l|}{ Typo II } \\
\hline \multirow[t]{8}{*}{ Cold Bokkeveld } & $\mathrm{s}^{\circ}$ lst extract & - & - \\
\hline & $s^{\bullet}$ and extract & $s^{\circ} ?$ & CM55 \\
\hline & $s^{\circ} 3$ rd extract & $\mathrm{s}^{\circ} ?$ & CN56 \\
\hline & $\mathrm{SO}_{4}=\left(\mathrm{H}_{2} \mathrm{O} \mathrm{sol}\right)$ & $(\mathrm{Mg}, \mathrm{Ca}) \mathrm{sO}_{4}$ & $\mathrm{CH} 43$ \\
\hline & $\mathrm{SO}_{4}=(\mathrm{HCl} \mathrm{sol})$ & - & - \\
\hline & $\mathrm{s}=(\mathrm{HCl}$ vol $)$ & Pes & CK45 \\
\hline & Res1dual 9 (aqua rogla) & - & - \\
\hline & Total $\mathrm{s}$ & & \\
\hline \multirow[t]{3}{*}{ Mighe1 } & $\mathrm{s}^{\circ}$ lat extract & - & - \\
\hline & $s^{0}$ 2nd extract & $\mathrm{s}^{\circ} ?$ & \\
\hline & $s^{0} 3 r a$ extract & $g ?$ & cu57 \\
\hline
\end{tabular}




\begin{tabular}{|c|c|c|c|}
\hline S Content & 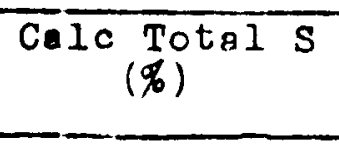 & $\begin{array}{l}\delta s^{34} \\
\left(0 / \rho_{0}\right)\end{array}$ & $\begin{array}{c}\text { Calc Av } \delta s^{34} \\
(\% / 00) \\
\end{array}$ \\
\hline 1.35 & & +1.8 & \\
\hline 0.09 & & - & \\
\hline 2.47 & & -1.6 & \\
\hline 0.13 & & +0.0 & \\
\hline 0.04 & & $+3 \pm 1$ & \\
\hline Traco & & - & \\
\hline 5.96 & 5.54 & +0.0 & +0.35 \\
\hline 1.5 & & +1.0 & \\
\hline- & & $\begin{array}{l}+3.3 \\
-1.7\end{array}$ & \\
\hline \multicolumn{4}{|l|}{0.00} \\
\hline 0.03 & & -0.6 & \\
\hline 0.53 & & +0.2 & \\
\hline 1.05 & & +0.7 & \\
\hline \multicolumn{4}{|l|}{0.00} \\
\hline 0.01 & & +2.2 & \\
\hline \multicolumn{4}{|l|}{0.00} \\
\hline - & 1.62 & & $+0.5_{2}$ \\
\hline 0.00 & & - & \\
\hline \multicolumn{4}{|l|}{ Trace } \\
\hline 1.58 & & +0.4 & \\
\hline
\end{tabular}


$\mathrm{SO}_{4}=\left(\mathrm{H}_{2} \mathrm{O} \mathrm{sol}\right)$

$(\mathrm{Mg}, \mathrm{Ca}) \mathrm{SO}_{4}$

CM44

$\mathrm{SO}_{4}=(\mathrm{HCl}$ sol $)$

$\mathrm{S}=(\mathrm{BCl} \mathrm{vol})$

Fes

CM46

Residual s (aqua regia)

$?$

CM5I

Total S

Murray

$\mathbf{s}^{\circ}$

$\mathrm{SO}_{4}=\left(\begin{array}{ll}\mathrm{H}_{2} \mathrm{O} & \mathbf{8 0}\end{array}\right)$

$\left(\mathrm{Hg}_{\mathrm{g}}, \mathrm{C}_{\mathrm{a}}\right) \mathrm{so}_{4}$

CMl丷

$\mathrm{SO}_{4}=(\mathrm{HCl} \mathrm{sol})$

$\mathrm{CaSO}_{4}$

CMI 4

$\mathrm{S}=(\mathrm{HCl} \mathrm{vol})$

Fes

CM13

Residual s (aqua regia)

$?$

CM17

Total $\mathrm{s}$

Type III

Moko 1a

$s^{\circ}$

$\mathrm{SO}_{4}=\left(\mathrm{H}_{2} \mathrm{O} \mathrm{sol}\right)$

$\mathrm{CaSO}_{4} ?$

CM15

$\mathrm{SO}_{4}=(\mathrm{HCl} \mathrm{sol})$

$\mathrm{s}=(\mathrm{BCl}$ vol $)$

FeS

CM16

Residual s (aqua rogia)

$?$

Cu18

Total S

HU3/71

Moko1a chondrules

$\mathrm{s}=(\mathrm{HCl}$ vol $)$

FoS

Fel 1x

$\mathrm{s}=(\mathrm{HCl}$ vol $)$

FeS

CMII

Lance

$s=($ HCl vol $)$

FeS

CM39 b

Warrenton

$\mathrm{s}=(\mathrm{HCl}$ vol $)$

FeS

CM40b

Residual s (aqua regia)

Karoonda

$S=($ HCl vol $)$

Fes

$\mathrm{SO}_{4}=(\mathrm{HCl} \mathrm{sol})$

$\mathbf{s}^{\circ}$

$\mathrm{s}^{0}$ ?

HU6/91

THBLE 2
CUT3

Residuel $\mathrm{s}$

$(\mathrm{Fe}, \mathrm{N1})_{9} \mathrm{~s}_{8}$

HU7/9O

HO1 $/ 70$ 
0.00

$+2.5$

1.71

$+0.3$

2.26

$<0.01$

1.83

1.18

1.60

Traco

0.02

0.00

0.13

1.25

1.02
1.83

1.18

1.60

$+0.4$ $+0.5$

$+0.5$ $+0.4$

$+0.4$

$-0.2$

- 0.2

$+0.2$ 


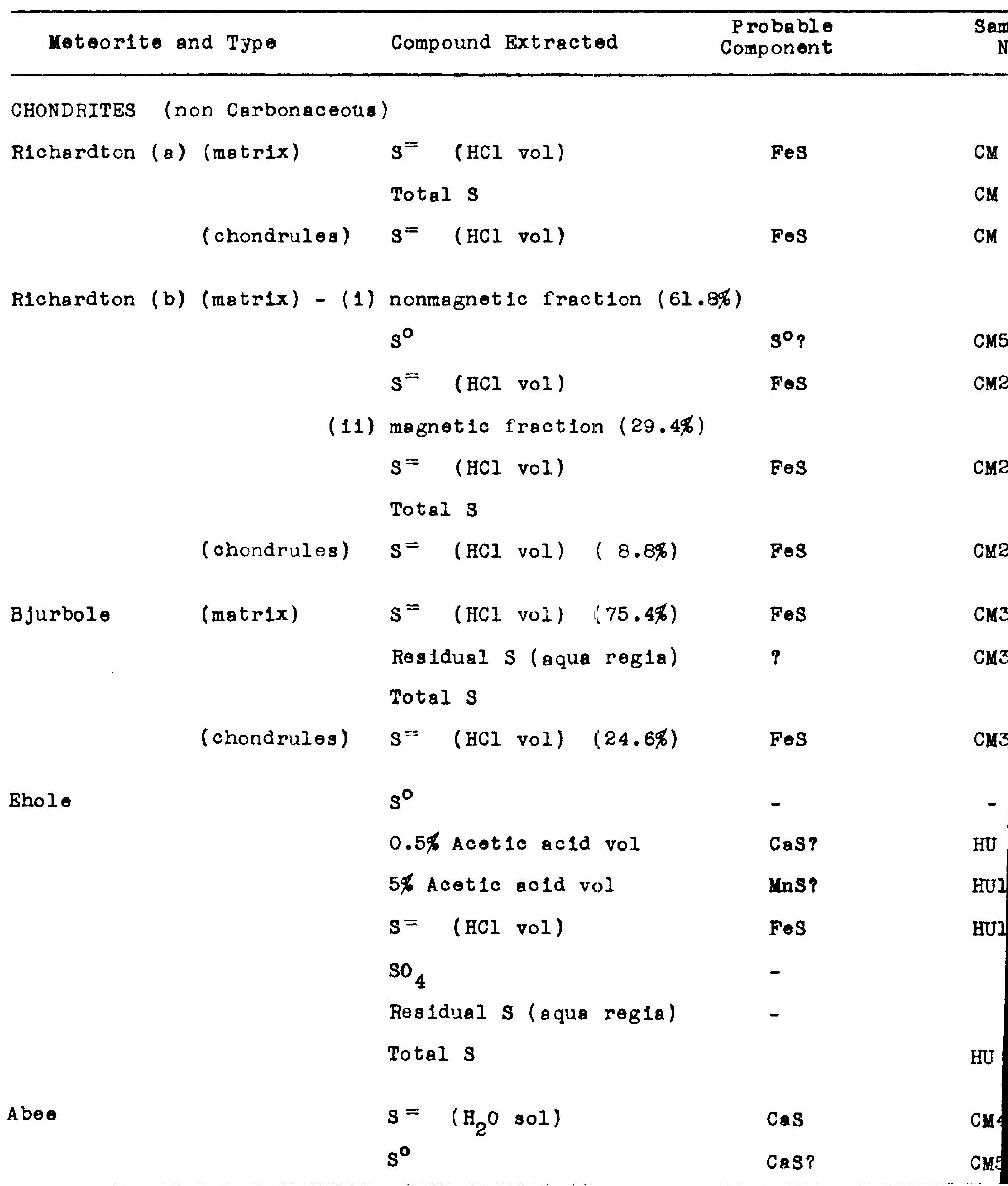


$20 \%$ Acetic acid vol (0-18 hrs.)

$20 \%$ Acetic acid vol

Mns? (18-20 hrs.)

$\mathrm{s}=(\mathrm{HCl} \mathrm{vol})$

Fes

CM5

Residual S (aqua rogla)

Total $\mathrm{S}$

Hvittis

$\mathrm{S}=\left(\mathrm{H}_{2} \mathrm{O}\right.$ sol $)$

$\mathrm{SO}_{4}=\left(\mathrm{H}_{2} \mathrm{O}\right.$ sol $)$

$\mathrm{s}=(\mathrm{HCl}$ sol)

$\mathrm{SO}_{4}=(\mathrm{HCl}$ sol $)$

Residual s (aqua regia)

Total S

ACHONDRITES

Norton County

IRONS (Trollite Phase)

Canyon Diablo (a)

(b)

(c)

Toluca

(a)

(b)

Merceditas

Indian Valloy

Ballinoo

Coahuila

TERRESTRIAL TROILITE

Del Norto County (Calif.)

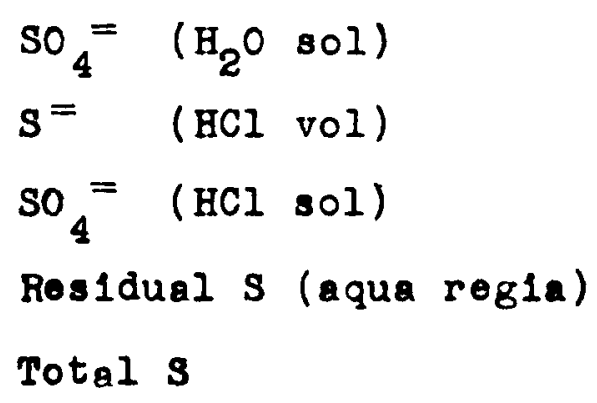

Cas

Cas?

CM3

Fos

CM3

CM3

$(F \in, N 1)_{9} s^{3}$

CM3

Ces?

CH3

Fes

Cu3

\section{$(\mathrm{Fe}, \mathrm{N1})_{9} \mathrm{~S}_{8}^{?}$}

CMYI

HU5

Fos

$\mathrm{CM}$

FoS

CM

Pes

$M / 1$

FeS

$\mathrm{CM}$

Fes

$M / 1$

Fes

Fes

Fes

FøS

$\mathrm{F} \odot \mathrm{Cr}_{2} \mathrm{~S}_{4}$

$\mathrm{CM}$

CM

CM

CM2

CM2

FeS

CM2]

\section{TABLE 3}


0.00

$\begin{array}{lc}0.06 & +2.5 \\ 0.04 & -0.3 \\ 0.12 & +0.1 \\ 0.00 & - \\ 0.24 & +0.2\end{array}$

3.46

0.13

0.34

0.00

0.18

0.35

17.3

25.8

35.7

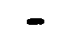

31.8

10.8

14.4

29.0

0.07
$-5.6$

$+0.0$

$+1.4$

$+0.0$

$-0.76$

$+0.0$

$+0.0$

$+0.1$

$+0.1$

$+0.0$

$+0.0$

$+0.1$

$+0.1$

$+0.1$

$+0.1$

$+0.3$

$+0.3$

$+0.0$

$+0.0$

$+0.6$

$+0.6$

$+0.4$

$+0.4$

25.8

$-2.3$ 